\title{
En el mundo poético de Garcilaso: desde el circulus vitiosus del amante hasta el tiempo cíclico del mito
}

\begin{abstract}
Aunque es cierto que el endecasílabo de Dante y Petrarca fue imitado en la Península ya desde el siglo xv, se debe sin embargo a Garcilaso y Boscán, lectores de Sannazaro, Bembo y Bernardo Tasso, su definitiva aclimatación en el canon poético español. Y es que la novedad de Petrarca, lo que Bernardo Tasso y Herrera llamarán su leggiadria, no había sido entendida antes de I500. También en el dominio de la sintaxis y el ritmo, los poemas de Garcilaso suponen un paso adelante: los hay, como el soneto XI o la estrofa inicial de la Canción III, sin punto hasta el final, lo que les confiere una estructura unitaria y redonda. Volvemos a encontrar la figura del círculo en la Égloga tercera donde el poeta trata de superar el tiempo a través del mito: inscribir el tiempo de la existencia en el orden cíclico del mito constituye, de hecho, la suprema ambición del poeta toledano.
\end{abstract}

Keywords: Endecasílabo, Petrarca, leggiadria, Garcilaso, estructuras circulares, tiempo cíclico.

\section{El endecasílabo en España: las razones de un triunfo}

En su breve carrera poética, Garcilaso manifestó clara preferencia por las formas métricas italianas: si prescindimos de las ocho coplas castellanas, donde naturalmente utilizó los versos de arte menor, no encontramos en su obra sino sonetos, canciones petrarquescas (o estrofas compuestas según ese mismo esquema), tercetos (entre estos, algunos encadenados con rima interior), endecasílabos sueltos, una lira (que, por más que se asemeje a la oda horaciana, es una combinación de endecasílabos y heptasílabos) y una égloga compuesta de octavas reales. El verso predominante en todos estos géneros es el endecasílabo: más del $75 \%$ de los versos escritos por nuestro poeta lo son y, si a estos les agregamos los heptasílabos, que constituyen otra novedad renacentista, llegamos a un porcentaje muy alto, alrededor del 90\% de su producción poética en castellano. Esto nos obliga a reflexionar sobre las excelencias de este verso, que había sido ensayado ya desde el siglo xv por Francisco Imperial y el Marqués de Santillana, pero que solo consiguió su aclimatación perfecta gracias a Boscán y Garcilaso.

En su Carta a la Duquesa de Soma, reproducida en el comienzo del segundo libro de sus obras, Juan Boscán recuerda las principales objeciones que algunos literatos de España habían hecho a la nueva moda de los versos italianos: 
Los unos se quexaban que en las trobas desta arte los consonantes no andavan tan descubiertos ni sonavan tanto como en las castellanas. Otros dezían que este verso no sabían si era verso o prosa [en efecto, el endecasílabo puede tener carácter tanto discursivo como propiamente lírico]. Otros argüían diziendo que esto principalmente havia de ser para mugeres y que ellas no curavan de cosas de sustancia sino del son de las palabras y de la dulçura del consonante (Boscán I999: II6).

Boscán replica a las críticas de los detractores de la nueva poesía en un tono no menos condescendiente, dejando entrever la existencia de una verdadera batalla cultural, en que a la nueva estética basada en la mentalidad humanista, urbana o cortesana, se le opone otra, tradicionalista y, en cierta medida, todavía medieval:

Y hanme parecido tan livianos sus argumentos, que de solo haver parado en ellos, poco o mucho me corro, y así me correría agora si quisiese responder a sus escrúpulos. Que ¿quién ha de responder a hombres que no se mueven sino al son de los consonantes? ¿Y quién se ha de poner en pláticas con gente que no sabe qué cosa es verso, sino aquél que calçado y vestido con el consonante os entra de un golpe por el un oído y os sale por el otro? Pues a los otros que dizen que estas cosas no siendo sino para mugeres no han de ser muy fundadas, ¿quién ha de gastar tiempo en respondelles? Tengo yo a las mugeres por tan sustanciales, las que aciertan a sello, y aciertan muchas, que en este caso quien se pusiese a defendellas las ofendería. Así que estos hombres y todos los de su arte, licencia ternán de dezir lo que mandaren, que yo no pretiendo tanta amistad con ellos que, si hablaren mal, me ponga en trabajo de hablar bien para atajallos. Si a éstos mis obras les parecieren duras y tuvieren soledad de la multitud de los consonantes, ahí tienen un Cancionero, que acordó de llamarse General, para que todos ellos bivan y descansen con él generalmente (II6-II7).

Si consideramos desde un punto de vista histórico las consecuencias de esta querella, esto es, la adopción de los nuevos metros por parte de la gran mayoría de los poetas castellanos si no a partir de I543, año de la editio princeps de las Obras de Boscán y Garcilaso, ciertamente después de I570, queda claro que el catalán había captado, mejor que nadie, el espíritu de la época ${ }^{I}$.

\footnotetext{
I Sabido es que el Cancionero General se edita nueve veces entre I5II y I573, pero, de estas impresiones, siete pertenecen a la primera mitad del siglo y solo dos a la franja 1550-1580. Fue asimismo notable el éxito comercial de Las obras de Boscán y algunas de Garcilaso de la Vega repartidas en cuatro libros (Barcelona, Carles Amorós, I543), con más de diez ediciones antes de alcanzarse el medio siglo, y algunas impresas en Francia e Italia. José Manuel Blecua comenta así la convivencia de los dos estilos: «Pero lo más curioso [...] es que la vieja poesía siguió conviviendo con la nueva, aunque también es verdad que las más altas cimas de la poesía del Renacimiento Garcilaso, fray Luis de León, Aldana, Herrera y san Juan de la Cruz se deberán a las novedades italianas» (Blecua I982: 9).
} 
Boscán era, en efecto, barcelonés; Garcilaso, toledano con algo de napolitano: ambos habían vivido en ambientes urbanos y cortesanos, y habían viajado por Europa (Boscán, como enviado del Emperador, a Viena; Garcilaso, en tanto que militar y representante del ideal humanista «de las armas y las letras», a Génova, Boloña, París, Flandes, Ratisbona, Viena, Nápoles, Túnez y el Sur de Francia, donde murió); ambos, además, estaban relacionados con la élite cultural de Italia; con Baldassarre Castiglione, el autor de El cortesano (traducido a la lengua castellana por Boscán), con Andrea Navagero (el embajador de Venecia, quien le recomendó escribir versos a la italiana) y, sobre todo, con el medio literario de Nápoles, compuesto por Bernardo Tasso, Luigi Tansillo, Antonio Sebastiano Minturno, Giulio Cesare Caracciolo, las hermanas Sanseverino y otras eminentes personalidades.

Ahora bien: es interesante observar que el prestigio del endecasílabo no era el mismo en Italia y en España. En su patria, si es que fue Italia y no Provenza la patria del endecasílabo ${ }^{2}$, este verso se consideraba, en palabras del Dante, como el «verso supremo», poderoso y a la vez versátil, el mejor de todos por extensión rítmica, variedad tonal y capacidad de acoger «todo género de vocablos, construcciones y pensamientos complejos» (Alighieri 1975: II, v, 5)3. Según el autor del De vulgari eloquentia, la nobleza del endecasílabo deriva de su capacidad para vehicular pensamientos elevados. En su Divina Comedia, en efecto, Dante aborda muy diversos asuntos filosóficos y teológicos: todo el saber de su época tiene cabida en sus tercetos. A ensalzar aún más el prestigio del endecasílabo contribuyó, medio siglo después, la fama de un poeta como Petrarca, admirado primero como escritor en latín y excelente conocedor de la antigüedad (hasta la época del Marqués de Santillana, este es su perfil). Pero la imagen de Petrarca cambió significativamente a principios del siglo XVI, cuando fue canonizado como el poeta lírico por antonomasia, a hora sí como autor en lengua italiana, y como tal imitado en las principales naciones de Europa ${ }^{4}$. Entre sus primeros admiradores se sitúa Juan del Encina, convencido de que «en la lengua italiana [ha] habido muy más antiguos poetas que en la nuestra, así como el Dante y Francisco Petrarca», aunque se abstiene de expresarse sobre los méritos del Petrarca lírico (Porqueras de Mayo 1986: 8I). Boscán, en su imitación de los sonetos XXXV («Solo e pensoso») y CXLV («Ponmi ove il sole») y de algunas de las canciones petrarquescas más famosas, muestra mayor familiaridad con el Canzoniere. Pero para encontrar un juicio propiamente estético al respecto,

2 Sobre esta discusión véase Beltrami (2015: 189-24I).

3 Es nuestra la traducción.

4 Para la fortuna del Petrarca lírico fue fundamental la edición de Aldo Manuzio, realizada en I50I bajo la supervisión de Pietro Bembo y a partir de uno de sus manuscritos, el Vaticano Lat. 3197. Poco después, sin embargo, Bembo descubre otro códice, el Vaticano Lat. 3195, cuyo orden será adoptado en las ediciones subsiguientes. Véase Dionisotti (1960: 9-70). 
hay que llegar a Fernando de Herrera, quien aprecia la «suavidad y dulzura» de la poesía amatoria de Petrarca y elogia, en su comentario sobre la canción petrarquesca, su leggiadria, palabra empleada por él en italiano como sinónimo de gracia y elegancia (Herrera 200I: 27I). Para Herrera, y cito de otra página de sus Anotaciones, el soneto es «la más hermosa composición y de mayor artificio y gracia de cuantas tiene la poesía italiana y española» (265), a lo cual añade que

[...] debemos a Francisco Petrarca el resplandor y elegancia de los sonetos, porque él fue el primero que los labró bien y levantó en la más alta cumbre de la acabada hermosura y fuerza perfecta de la poesía, aquistando en aquel género, y mayormente en el amatorio, tal gloria, que en espíritu, pureza, dulzura y gracia es estimado por primero y último de los nobles poetas, y sin duda, si no sobrepujó, igualó a los escritos de los más ilustres griegos y latinos (Herrera 200I: 27I) .

El arte con que Petrarca supo moldear el endecasílabo nos parece, aún hoy, simplemente prodigioso. En su soneto XC, por recordar uno de los más famosos, «Erano i capei d'oro all'aura sparsi», el poeta canta la belleza de Laura vista a través del recuerdo, entre la discontinuidad (porque el tiempo amenaza con destruirla) y la continuidad (del sentimiento de amor que permanece), es más: entre la disyunción temporal (que se manifiesta en los verbos en el pretérito y en las reflexiones que acusan la distancia respecto del pasado) y la conjunción (de los verbos en el imperfecto, con esas rimas vocálicas permeables en -ea: «avolgea», «ardea», "parea», «avea», y de los momentos de identificación con el pasado). Para facilitarles la lectura, voy a recordar los principales aspectos temáticos de la descripción de Laura: el primer cuarteto habla de sus cabellos esparcidos en el viento y de sus ojos; el segundo, de su cara; en el primer terceto se evoca su modo de andar elegante y su habla casi divina; y en el segundo terceto se resume la reflexión inherente a este texto sobre las dos maneras de concebir la relación con el pasado, disyuntiva y conjuntiva:

Erano i capei d'oro a l'aura sparsi, che ,n mille dolci nodi gli avolgea, e ,l vago lume oltra misura ardea di quei begli occhi ch'or ne son sì scarsi; conjunción

(presencia en el recuerdo)

disyunción

(conciencia del cambio)

5 Este pensamiento acerca de un Petrarca emulador de los poetas antiguos, expresado además con la misma formulación, se encuentra ya en Bernardo Tasso, Ragionamenti della poesia (1562), véase Weinberg (1972: II, 569-584). Allí se lee: «Petrarca, il quale ha se non superato almeno qual si voglia poeta greco o latino con la lirica dolcezza agguagliato» y aparece asimismo el término «leggiadria». Herrera no solo hace suyo ese juicio, sino que lo reproduce al pie de la letra (574). 
e ,l viso di pietosi color' farsi, non so se vero o falso, mi parea: conjunción l'esca amorosa al petto avea, (se sitúa de nuevo en el estado dudoso) qual meraviglia se di subito arsi?

Non era l'andar suo cosa mortale, ma d'angelica forma, et le parole sonavan altro, che pur voce humana:

uno spirto celeste, un vivo sole fu quel ch'i' vidi; e se non fosse or tale, piaga per allentar d'arco non sana ${ }^{6}$.

disyunción hipotética > conjunción

En el soneto XC, Petrarca consigue espiritualizar lo sensual y encarnar lo espiritual en un inolvidable retrato de mujer, envuelto en una atmósfera mágica. Este soneto, donde el movimiento ondulante de los cabellos en el viento configura la sinuosidad del verso, por lo que se habla aquí no solo de Laura sino también de la propia poesía, representa un paso adelante en la historia del pensamiento europeo, y esta novedad, que consiste en el arte de unir la sensibilidad a la reflexión y esta a lo sensual y vivo, se expresa a través del endecasílabo. Más que un instrumento de la nueva cultura, el endecasílabo es pars pro toto del nuevo paradigma de los valores humanistas y del nuevo sentir que emana del arte italiano en el umbral del Renacimiento (pues a Petrarca le imitarán también los pintores): un arte basado en la concepción inmanente del ser humano, a quien se le considera ahora como unidad inseparable de cuerpo y alma, de pensamiento y emoción. La nueva poesía, en sus mejores manifestaciones, es recuerdo de emociones, reflexión sentida, unión-desunión entre el yo y la amada que algunas veces comparece ante el poeta en un escenario natural, y como ejemplo podríamos recordar la canción CXXVI, la de las «Chiare, fresche, e dolci acque», cuyo principio imita Garcilaso en su Égloga primera.

Es cierto que el endecasílabo, cuya versatilidad le distingue tanto del breve octosílabo como del pesado verso de arte mayor, comporta aún otras cualidades. Pedro Ruiz Pérez recuerda a este propósito que el nuevo verso

[...] representa la posibilidad de demostrar la flexibilidad del idioma y su capacidad de adaptación a una prosodia poética distinta; permite la imposición de un ritmo más pausado y propicio para la introspección meditativa; y se adecúa con más facilidad al encauzamiento de un ideal de llaneza expresiva, que no está reñido con una competición [...] con los modelos latinos, a los que remite por la señalada proximidad al hexámetro dactílico (Ruiz Pérez 1999: 19).

6 Petrarca (1996: 44I). Son nuestras la cursiva y las observaciones del margen derecho. 
En Italia, la generación de 1500-1530, la de Sannazaro, Bembo, Castiglione y Ariosto, recupera de los grandes autores del Trescientos cuyas obras salen ahora a millares de las imprentas ese culto del endecasílabo y lo propone nuevamente a los contemporáneos. Según Trissino, autor de una conocida Poética (1529), los vates de Italia, si desean componer epopeyas en versos heroicos, pueden recurrir como equivalente de los hexámetros latinos a los endecasílabos, no agrupados en tercetos u octavas reales, sino sencillamente sueltos, esto es, sin rima (Weinberg 1970: II,48). Su consejo será obviado, porque los grandes poetas épicos del Quinientos, como Tasso, Camoens y Ercilla, preferirán valerse de la octava, propia del poema caballeresco, con sus endecasílabos rimados. Después de Trissino, otros tratadistas confirmarán la aptitud del endecasílabo para el discurso heroico. Denores, un preceptista veneciano de la segunda mitad del siglo, considera este verso como «el más sonoro de todos» (jlos adversarios de Boscán habían sostenido exactamente lo contrario!), y es precisamente esa sonoridad la que lo privilegia para la poesía épica; para el teatro, según opina este crítico, era preferible utilizar los versos de siete y cinco sílabas, porque la articulación del diálogo se conseguía mejor con unidades métricas cortas (Weinberg I972: III, 4IO).

En la época de Bembo y de Garcilaso ya se conocían perfectamente las reglas de acentuación del endecasílabo: se sabía, por tanto, que el único acento obligatorio caía en la décima o penúltima sílaba, siendo, los demás, acentos rítmicos susceptibles de variar su posición con cierta libertad, de acuerdo con la argumentación y el fondo emotivo. El gran teorizador del endecasílabo petrarquesco es Pietro Bembo, en sus Prose della volgar lingua (I525): en su opinión, si el acento rítmico no cae ni sobre la cuarta ni sobre la sexta, no hay endecasílabo que merezca este nombre. En efecto, basta con modificar la posición de los acentos y lo que antes fue verso se convierte en prosa:

Per ciò che le prose [...] tuttavolta prose sono; dove nel verso puossi gli accenti porre in modo che egli non rimane più verso, ma divien prosa, e muta in tutto la sua natura, di regolato in dissoluto cangiandosi [dissoluto = libre, sin regla]; come sarebbe, se alcun dicesse: Voi, ch' in rime sparse ascoltate il suono; e Per far una sua leggiadra vendetta; o veramente Che s'addita per cosa mirabile, e somiglianti. Ne' quali mutamenti, rimanendo le voci e il numero delle sillabe intero, non rimane per tutto ciò né forma, né odore alcuno di verso. $\mathrm{E}$ questo per niuna altra cagione adiviene, se non per lo essere un solo accento levato del suo luogo in essi versi, e ciò è della quarta o della sesta sillaba in quelli, e della decima in questo. Ché, con ciò sia cosa che a formare il verso necessariamente si richiegga che nella quarta o nella sesta o nella decima sillaba siano sempre gli accenti, ogni volta che qualunque s'è l'una di queste due positure non gli ha, quello non è più verso, comunque poi si stiano le altre sillabe (Bembo I967: 77-78). 
Las disquisiciones teóricas de Bembo, por más que desatiendan los acentos complementarios, han sido determinantes para la métrica italiana. En ella se distingue, comúnmente, entre el endecasílabo a maiore (con el acento rítmico en la sexta y la cesura principal inmediatamente después, lo que divide el verso en dos hemistiquios) y el endecasílabo a minore (con el acento rítmico en la cuarta, también antes de la cesura). En España se conoce aún otra tipología, basada en el criterio de la posición de los acentos rítmicos: según este criterio, que se remonta en parte a las poéticas del siglo XVI y, señaladamente, al Arte poética de Minturno7 ${ }^{7}$, se tiene en cuenta la posición del acento inicial, lo que permite distinguir cuatro clases de endecasílabos: enfático, heroico, melódico y sáfico. Ni que decir tiene que son posibles otras diferenciaciones más sofisticadas, si se consideran también los acentos complementarios y sus numerosas combinaciones ${ }^{8}$. Pero la terminología que acabamos de recordar no deja de ser problemática, porque no todo endecasílabo con los acentos en la segunda y la sexta tiene que ver con lo heroico; y tampoco se comprende por qué un verso con los acentos en la tercera y la sexta debería resultar más melódico que otros. Lo cierto es que existe una gran libertad para colocar los acentos complementarios y flotantes, y que las distintas cadencias se acompasan con el fluir del pensamiento y el ímpetu de las emociones.

El modo de expresarse en el endecasílabo es, de hecho, orgánico, y esto representa otra importante novedad, porque el verso sigue el movimiento de la reflexión y del sentir. No son las rimas las que imponen a cada paso unas palabras fonéticamente similares, es el movimiento de la reflexión sentida el que se traduce orgánicamente en ritmo; tampoco son los juegos verbales más cerebrales como el políptoton o la figura etymologica los que crean los efectos estilísticos más sobresalientes, ya que la intención del poeta no es la de estimular el mero intelecto, sino la de envolver a la entera persona del lector. Pero, ¿qué significa expresarse de modo «orgánico»? Tómese el caso del ritmo yámbico que se da con cierta frecuencia en el endecasílabo: cuando se presenta en su forma más pura, adquiere un valor icástico, por sugerir un movimiento semejante a los pasos humanos: «Nel mezzo del cammin di nostra vita / mi ritrovai in una selva oscura», y aquí quien camina es Dante-personaje; o bien, cuando Garcilaso, en el soneto III, cuando habla de los continuos desplazamientos que le obligan a abandonar a su dama, se vale de un ritmo análogo: «La mar en medio y tierras he dejado / de cuanto bien, cuitado, yo tenía». Pero la poesía, más que imitar la vida, crea un

7 Minturno (2009). Minturno conoce el verso sáfico toscano, con los acentos en la cuarta, sexta y octava (2009: II, 843). Véase Navarro Tomás (I973: 88-II5).

8 La tipología basada en el criterio de la posición del acento inicial se encuentra en Navarro Tomás (1982: $\$ \$ 104-106)$. Desde entonces se han propuesto nuevas clasificaciones, como la de Miguel Ángel Márquez (2009: II-38). 
simulacro de realidad a través del lenguaje y de sus recursos retóricos: no reproduce los movimientos físicos o psíquicos reales, sino que sugiere una particular trama rítmica que percibimos como análoga a la que imaginamos que afecta al referente (o al personaje representado). En el soneto IV, por ejemplo, el yo lírico de Garcilaso, hablando desde una situación de encierro o confinamiento, proclama con determinación su voluntad de superar cualquier obstáculo que lo separe de su amada, lo que se traduce en el violento enjambement del primer terceto, que acelera el movimiento del verso noveno y desplaza el acento principal hacia el final del la parte ascendente del periodo, a saber, sobre la expresión «romper un monte», en el verso décimo. Esto nos obliga a poner el mayor énfasis en esta expresión y a leer: «Yo mismo emprenderé a fuerza de brazos / romper un monte, que otro no rompiera, / de mil inconvenientes muy espeso» (vv. 9-II). Es cierto que el sintagma «a fuerza de brazos», con sus acentos en octava y décima, surte a su vez un efecto icástico, ya que nos transmite la imagen del combatiente mientras se abre paso golpe a golpe. Pero el acento más fuerte cae en la última parte del sintagma, esto es, en el comienzo del verso décimo.

La posibilidad de abordar temas filosóficos, cosmológicos, científicos, y de suscitar con ellos la admiratio constituye otro rasgo característico del endecasílabo. No olvidemos que, debido a la contracción silábica producida por los fenómenos de la sinalefa y de la sinéresis, el endecasílabo puede contener más de las consabidas once sílabas, lo que le permite expresar asuntos sumamente complejos: como cuando Torquato Tasso, en el comienzo de su Jerusalén, inmediatamente después del proemio, habla del ojo de Dios, figura de la omnisciencia y del saber poético, que abarca con una sola mirada toda la variedad del mundo en una especie de percepción simultánea de todo lo existente, de totum simul, y concentra ese concepto de la variedad en la unidad en un solo dístico que comprende asimismo una multitud impresionante de sílabas: «quando da l'alto soglio il Padre eterno,/ [...] gli occhi in giù volse, e in un sol punto e in una / vista mirò ciò ch'in sé il mondo aduna» (el penúltimo verso de esta estrofa, una octava real, comprende en sus once sílabas métricas nada menos que diecisiete sílabas fonológicas y, el último, aún trece) (Tasso I97I: I5). Si me piden un ejemplo español con análogo artificio, les propondré ese célebre verso de Góngora, el último de su soneto sobre el Carpe diem, que contiene quince sílabas fonológicas en sus once sílabas métricas («en tierra, en humo, en polvo, en sombra, en nada»), dispuestas, además, en magnífica escala descendente, por evocar sustancias cada vez menos consistentes.

Gracias a las Anotaciones a Garcilaso de Fernando de Herrera y a las Obras de Garcilaso comentadas por el Brocense, también la España imperial tiene sus poéticas, que, como antes hemos comprobado en el caso del hispalense, no excluyen los versos italianos. Todo lo contrario: los consideran ya como 
suyos propios, después de haberlos integrado en la tradición nacional ${ }^{9}$. Con la canonización de Garcilaso en torno a I580 este proceso de aclimatación ha concluido ${ }^{\mathrm{IO}}$. Pero no todos los tratadistas de esta época reconocen el papel determinante de los dos mayores poetas del Renacimiento español. He aquí cómo otro sevillano, Juan de la Cueva, en su Ejemplar poético de I6o6, interpreta la historia del endecasílabo. Ante todo, le importa mostrar que no se trata de un producto de importación, sino de un verso originariamente hispano: Galicia y Cataluña, argumenta, conocían ya desde la Edad Media el decasílabo provenzal, del que deriva el verso de Dante y Petrarca (el propio Dante, en su De vulgari eloquentia, cita como ejemplos algunos versos de trovadores). Pero hay algo más: Juan de la Cueva no está dispuesto a reconocer el gran mérito de Garcilaso y Boscán; le importa más destacar la aportación del Marqués de Santillana para alegar la existencia de una larga tradición autóctona de este verso. Con todo, su preocupación por hacer del endecasílabo un fenómeno nacional es bastante ingenua, porque no se dice en ningún momento que la importación de este verso por Garcilaso y Boscán, y con ello el estilo petrarquesco, comportasen un significativo cambio de valores. En la poética de Juan de la Cueva falta por completo la reflexión sobre el cambio de calidad que implicó esta innovación, como se puede ver en el siguiente fragmento:

\section{Ejemplar poético, II}

Fueron siempre estas dos composiciones, (la copla y el romance) tenidas en España en grande estima hasta que entraron nuevas invenciones.

Llamo nuevas, que el número a la rima del grave endecasílabo, primero floreció, que en el Lacio, en nuestro clima.

El provenzal antiguo, el sacro ibero en este propio número cantaron, antes que dél hiciese Arno, impero.

9 En sus Anotaciones a la poesía de Garcilaso, Herrera sostiene de forma inequívoca: «Los españoles, que no perdonaron a algún género de verso italiano, se han ya hecho propia esta poesía» (Herrera 200I: 275).

Io El proceso de canonización de Garcilaso se pone en marcha con la primera impresión exenta de sus obras, sin los versos de Boscán (I569). Este texto servirá de base para la primera edición comentada «con anotaciones y enmiendas del Licenciado Francisco Sánchez [de las Brozas]», en Salamanca, en la imprenta de Pedro Lasso en el año I574. El Brocense incorpora en ella cinco coplas y seis sonetos inéditos, y otros tres nuevos sonetos en la segunda edición, de 1577. Tres años después, en I580, verán la luz las Anotaciones de Herrera. Otra edición comentada, la de Tamayo de Vargas, en I622, cae ya fuera de la cronología de estas consideraciones. Véase sobre ello Antonio Prieto (1984: 9I). 
El Dante y el Petrarca lo ilustraron y otros autores y esto les debemos, a ellos que de nosotros lo tomaron.

La justa posesión que dél tenemos que a la musa de Tajo y catalana (Garcilaso y Boscán) se atribuye, tampoco la apliquemos.

Primero fue el Marqués de Santillana quien le restituyó de su destierro y sonetos dio en lengua castellana.

He querido aclarar el ciego yerro en que viven aquellos que ignorando esto, siguen la contra yerro a yerro.

El que en ellos escribe irá notando la variedad de suertes que hay en ellos que van sujetos varios demandando.

Mas tienes de advertir en el hacellos que tengan once sílabas y mires la contextura que los hace bellos.

Y que siempre te guardes y retires que en agudo no acabes el acento porque la una sílaba no tires.

Boscán dijo sin más conocimiento: «aquella reina que en la mar nació», y usó deste troncado abatimiento.

Y Garcilaso dijo y no advirtió: "Amor, amor, un hábito vestí» y don Diego en mil versos los usó.

Lo mesmo ahora habrá de ser de mí que citando los versos que dijeron incurro en los que siempre aborrecí.

(De la Cueva I965: I5I-I89)

Garcilaso, efectivamente, tiene un soneto, el número XXVII, «Amor, amor, un hábito vestí», con cuatro rimas agudas, que, sin embargo, pronunciadas a la latina o a la italiana, valdrían como dos sílabas (vestí=ital. vestii, lat. vestivi: mí=puede entenderse como contracción de mihi). El poeta valenciano ya juega con el doble sentido de la palabra «hábit», esto es, 
el de «costumbre» y el de «vestido». Curiosamente, el Brocense ofrece otra versión de este soneto en rimas llanas, pero no sabemos si es de Garcilaso («Amor, amor, un hábito he vestido / del paño de tu tienda bien cortado»). En todas estas composiciones - hay otra análoga de Hurtado de Mendoza- se propone la metáfora del vestido como indumentum animae, con que la tradición neoplatónica designaba a la imaginación y, en este caso, a la dolorosa fabulación del amante (De la Vega 2017: I83-I85).

\section{La importancia del ritmo}

En los estudios propedéuticos se nos ha enseñado a distinguir entre los planos del discurso, principalmente entre la enunciación y el enunciado y, dentro de este último, entre la forma del contenido y la de la expresión, que a su vez se compone de diferentes elementos o aspectos, a saber: el metro, la sintaxis y el sonido. También se nos ha explicado que los significados del plano de la expresión no son de tipo conceptual, sino de tipo tímico (por ej.: eufórico vs. disfórico), ya que influyen en la sensibilidad del lector y alteran sus emociones. Adviértase, con todo, que a la hora de interpretar un texto no conviene considerar por separado, ni comentar aisladamente, las observaciones relativas a cada uno de estos aspectos; es necesario relacionarlas unas con otras y examinar los efectos que resultan de la cooperación entre los distintos planos. Y es que en la combinación de los elementos métricos con los sintácticos se origina el ritmo, que es un componente fundamental de la significación.

Los lectores no muy experimentados en el arte de la interpretación suelen prestar una atención exagerada a los sonidos. Buscan acumulaciones de vocales o de consonantes, que algunos coleccionan sin comentarlas y otros conectan mecánicamente con los datos semánticos, sosteniendo, por ejemplo, de una cadena de us, que «sugiere oscuridad». No es este un modo correcto de proceder. Si el texto abunda en vocales velares, hay que empezar construyendo una oposición entre estas y las vocales palatales, sin invadir inmediatamente el plano semántico; posiblemente exista en este una oposición temática análoga, que ha de ser identificada y descrita como tal. Ese modo de señalar la inusitada frecuencia de un sonido o de relacionar el componente fónico con un supuesto valor expresivo se encuentra incluso en ediciones serias. Así, Julián Jiménez Heffernan, en la más reciente edición comentada de la Poesía castellana de Garcilaso, observa, a propósito de la estrofa inicial de la Canción tercera, que «es muy notable la aliteración que provoca la líquida /r/ a lo largo de esta estrofa» y acaba enumerando unas quince palabras con erre («ruido», «corriente», «pudiera», «lugar», «descansara», «agora», «tristura»... hasta «ruiseñor»), pero se abstiene de interpretar este dato (De la Vega 20I7: 247). Aparte del hecho de que no siempre se trata de 
aliteración, sino más bien de repetición -en la lengua española, es verdad, se admite el uso extenso del término «aliteración», no referido exclusivamente a las letras iniciales-, se debería tener en cuenta, más bien, la oposición entre /r/ y /l/, puesto que en la misma estrofa encontramos las palabras «isla, clara, lugar, las flores, placer, blandas querellas, la, los, el, ellas». Sabido es que /r/ es la líquida áspera y /l/ su pendant blando. En un contexto que describe un locus amoenus, eufórico por definición, pero que se revela como un lugar del destierro, idea evidentemente disfórica, debe de haber un contraste también en el nivel fonético, es decir, una mezcla de sonidos ásperos y blandos: /r/ vs. /l/ o bien, una alternancia de oclusivas sordas y sonoras: «cerca el Danubio una isla que puDiera / ser lugar escogiDo / para que Descansara / quien, como esTó yo agora, no esTuviera» (vv. 3-6). Se habla en esta canción, además, del «manso ruïdo», lo que nos obligaría a tomar en consideración también la función de las nasales. Pero dejemos el análisis fonético, en el que, repito, es aconsejable proceder por oposiciones antes de reflexionar sobre las estructuras del contenido. Con todo, es mucho más importante analizar el ritmo, que resulta en primer lugar de la tensión que se crea entre las unidades métricas y las sintácticas y, en segundo lugar, de la economía global del discurso, que se percibe al comparar el comienzo con el final o, en un soneto, los cuartetos con los tercetos.

En las composiciones clásicas, el metro tiene reglas establecidas y canónicos esquemas de rima. La sintaxis, en cambio, resulta bastante flexible y variada: se nos presenta de forma continua o discontinua, relajada o más bien tensa, y en algunos casos incluso fraccionada, llamativamente inquieta. Cuando la unidad sintáctica coincide con la métrica, el efecto que se produce suele ser de escasa tensión, lo que es adecuado en el discurso o razonamiento contemplativo. Ello no significa necesariamente ausencia de sentimiento; puede haber una emoción de fondo como la tristeza del amante, pero en ese caso se percibe como afección no sujeta a mudanzas. Cuando en cambio se produce un súbito aumento de tensión, debido a la multiplicación de los encabalgamientos y de las rupturas sintácticas, nos las vemos con una poesía en alto grado emotiva. Como ejemplo de un soneto meditativo podríamos aducir el quinto de Garcilaso: «Escrito,stá en mi alma vuestro gesto / y cuanto yo escribir de vos deseo: / vos sola lo escribistes; yo lo leo / tan solo que aun de vos me guardo en esto» (vv. I-4). En este soneto no se produce ni un solo enjambement, pero se advierte un crescendo retórico hacia el final: «por vos nací, por vos tengo la vida, / por vos he de morir, y por vos muero» (vv. I3-I4).

Ahora bien, en la trayectoria poética de Garcilaso, tal como ha sido descrita por Rafael Lapesa, se observa, en una primera época, un verdadero culto de la queja amorosa y, por consiguiente, la predilección por la sintaxis agitada (con exclamaciones o preguntas sin respuesta); en su fase de ma- 
durez, empero, crece la tendencia a compensar o a superar el caos emotivo: bien éticamente, con una actitud estoica, que es típica de un joven noble educado según los principios del humanismo español -y un ejemplo magnífico de esta actitud se nos ofrece en la Canción tercera-, bien estéticamente, mediante la introducción de la distancia artística (como ocurre en el canto de Nemoroso, hacia el final de la Égloga primera). Dicho de otro modo, el poeta amante -esto es, su protagonista, el yo lírico- se nos aparece como víctima de sus pasiones y de su locura de amor; no se cansa de decir que su vida se le ha vuelto insoportable y que podría acabar pronto. Garcilaso dramatiza, a la manera de los poetas del Cancionero general, la lucha entre la razón y la pasión, y lo que prevalece suele ser la pasión. En la poesía de los últimos años, por más que se exasperen esos momentos de desesperación, advertimos la importancia de un arte de la compensación que permite reconquistar cierto equilibrio, si no de tipo moral, de orden estético; pero, en este último caso, quien lo consigue ya no es el poeta, sino la obra realizada por él ${ }^{\mathrm{II}}$.

Hemos aludido a la existencia de dos grandes periodos en la trayectoria de nuestro poeta. Desgraciadamente, la mayoría de las composiciones de Garcilaso no es datable, y solo a una reducida parte de ellas podemos asignar una fecha precisa. A la luz de la biografía del poeta, dos sucesos pueden haber favorecido un significativo cambio de estilo: su destierro en septiembre de I53I, hecho que, si comportó un aislamiento de varios meses cerca de Ratisbona, dio lugar asimismo a un periodo de meditación y de lecturas; o bien, su llegada a Nápoles en las postrimerías de I532, con la que comienza su segunda y más larga estancia italiana, destinada a durar más de tres años. Pues bien, a mí me parece que todo lo anterior a la primavera del año I532 pertenece aún a su primera manera; en cambio, lo que escribe a partir de la Canción III y sobre todo en Nápoles, corresponde a su madurez. Ello significa, concretamente, que los sonetos I, VI, XXVI, XXVII y XXXVII y las canciones I, II y IV pueden considerarse aún del primer periodo, mientras que los demás sonetos y las canciones III y V, así como las epístolas, elegías y églogas deben atribuirse a la plenitud de su estilo poético.

Comparemos ahora dos sonetos de periodos distintos, el número I y el número XI. Tratándose de sonetos, tienen, por supuesto, muchos elementos en común: por ejemplo, la tendencia a la pointe final (que, en los sonetos más filosóficos, como el núm. XXIII, corresponde a la sentencia concluyente) y el tema del desconsuelo: la desesperación del amante. Pero también difieren notablemente. En el número I, Lapesa advierte, a pesar del molde petrarquista, algunos rasgos característicos del estilo cancioneril: ante todo,

II Para más detalles véase mi lectura: «Garcilaso, Égloga primera: la adopción de la distancia estética» en Güntert (20I2: 3I-42). 
la frecuencia del políptoton (acabo, acabar, acabaré, acabarme; quisiere, querello; hará, hacello) (Lapesa I968²: 55). Nada de eso se repite en el soneto XI. Y si el número I es una de las composiciones más tempranas, el número XI, que recuerda a las ninfas tejedoras de la Égloga tercera, pertenece ciertamente a la culminación del arte de Garcilaso. La presencia de las ninfas o náyades, figuras que pertenecen a un más allá mítico, es un tema clasicista, que recuerda a Virgilio, el poeta de las Geórgicas, y a Sannazaro ${ }^{12}$. En cuanto a Petrarca, no desconoce el motivo, pero no lo desarrolla con el sentido que cobra aquí, donde las ninfas viven en moradas preciosas debajo del agua, pasan su tiempo escuchando historias de amor o labrando tapices, actividad con la que convierten las vidas humanas en obras de arte.

Sigamos con el cotejo. El soneto I comienza con un tono meditativo, y las unidades sintácticas, en un principio, no discrepan de las métricas; pero en el primer terceto, debido a los enjambements, se produce un crescendo implacable. Análogamente, en el plano del contenido se contraponen las actividades del sujeto consistentes en «contemplar y ver» las etapas de su vida, actitud que es propia de la razón, a la desorientación psíquica (cuarteto II) y a la crisis sin remedio, a la que aluden los tercetos. Se procede, por tanto, desde un momento meditativo hacia un estado de creciente agitación que culmina en la pregunta final. Cabe recordar que algunos críticos han propuesto una interpretación no erótica, sino política de este soneto, porque no se habla nunca explícitamente de la dama, sino solo de «quien sabrá perder» al sujeto, motivo por el cual ya el Brocense quiso introducir, en el verso II, el pronombre «ella» (De la Vega 20I7: I82). Pero, a mi modo de ver, el exclusivo dualismo de la relación y ciertas afirmaciones del yo como «más he yo sentido / ver acabar conmigo mi cuidado» (= mi cuidado amoroso) o «me entregué sin arte / a quien sabrá perderme» hacen más plausible una interpretación erótica de este texto. Leámoslo:

I

Cuando me paro a contemplar mi estado a ver los pasos por dó me han traído, hallo, según por dó anduve perdido, que a mayor mal pudiera haber llegado:

mas cuando del camino estó olvidado, a tanto mal no sé por dó he venido; sé que me acabo, y más he yo sentido ver acabar conmigo mi cuidado.
XI

Hermosas ninfas, que en el río metidas, contentas habitáis en las moradas de relucientes piedras fabricadas y en columnas de vidrio sostenidas,

agora estéis labrando embebescidas o tejiendo las telas delicadas, agora unas con otras apartadas contándoos los amores y las vidas:

I2 Rafael Lapesa señala como fuente del soneto XI dos pasajes de la Arcadia de Sannazaro (prosas VIII y XII) y el episodio virgiliano de Aristeo (Geórgicas, IV, 333-385). Véase Lapesa (I968 $2^{\mathrm{a}}$ ed.: I64 y nota 194). 
Yo acabaré, que me entregué sin arte a quien sabrá perderme y acabarme si quisiere, y aún sabrá querello; que pues mi voluntad puede matarme, la suya, que no es tanto de mi parte, pudiendo, ¿qué hará sino hacello?

(De la Vega 20I7: 127) dejad un rato la labor, alzando vuestras rubias cabezas a mirarme, y no os detendréis mucho según ando, que o no podréis de lástim escucharme, o convertido en agua aquí llorando, podréis allá despacio consolarme.

(De la Vega 20I7: I82)

El soneto XI, en cambio, está formado por un único periodo, y es de los pocos sonetos de Garcilaso que tienen esa elegante estructura. Entre los cuartetos y los tercetos hay solo una pausa fuerte, un doble punto, que separa la evocación inicial del reino de las náyades, creadoras de mitos, de la petición que el yo lírico les dirige: en esta describe su dolor como intolerable, tanto para las que van a escuchar su queja como para él mismo, que acabará disolviéndose en lágrimas, en agua, para integrarse, así, en el mundo de las ninfas tejedoras. Pero si el sujeto se disuelve, se sustrae a la existencia histórica para entrar en el más allá: en la dimensión del mito, de las telas y del texto. La estructura sintáctica del periodo único es propicia a la continuidad: se producen por lo menos tres enjambements, en los versos 3 , 7 y 9, y también hay cinco gerundios, indicios de simultaneidad: su redondez contribuye a volver más sinuoso el discurso. El tiempo del yo es el de la existencia, un tiempo necesariamente limitado; el de las ninfas, en cambio, es alternado («ahora - ahora») y circular. Bien mirada, la construcción sintáctica del período único hace pensar en un círculo que se cierra: entre el vocalismo de la palabra inicial «hErmOsAs [ninfas]» y el del final «consOlArmE» hay correspondencia, pues a la cadena /e-o-a/ hace eco la serie /o-a-e/ y a la primera secuencia consonántica (h)erm- responde análogamente el último grupo -rme. Son los mismos elementos, pero colocados en otro orden de sucesión. Y adviértase que las rimas de los tercetos ya no son abiertas como en el soneto I (CDE DCE), sino encadenadas, lo que confirma la idea del cierre, típica del círculo. Me parece sintomática esa insistencia en el tema circular, porque inscribirse en el círculo, que es figura perfecta, es aquí salirse del tiempo de la existencia para convertirse en poema o en mito.

\section{La conciencia artística del poeta}

En la última parte de mis consideraciones me gustaría evidenciar lo sumamente consciente que fue Garcilaso de sus procedimientos métrico-sintácticos. Cuando se trabaja con un método de orientación semiótica, lo que se espera entender mejor son las estructuras de los textos y no el pensamiento o el sentimiento del poeta. Existen, no obstante, algunas técnicas que nos permiten observar de cerca las preferencias estilísticas del autor y descubrir, si no sus secretos más personales, cuando menos la motivación 
de algunas de sus opciones. De esto me voy a ocupar en mis comentarios finales, que giran, aunque no exclusivamente, en torno a la figura del círculo.

De los cuarenta sonetos son pocos los que merecen la denominación de 'circulares'. Es verdad que el número XII se compone de un solo periodo, pero termina con una doble pregunta sin respuesta, indicio no tanto de un cierre, cuanto de una cuestión abierta, de un conflicto no resuelto. Es más interesante a este propósito el soneto XIV, que describe por medio de la alegoría una doble dependencia: la que existe entre el sujeto enamorado y su pensamiento enfermo, que le pide cada día el mismo veneno, y la que protagonizan el «niño doliente» y su madre, incapaz de negarle el alimento nocivo. Este soneto está formado, a su vez, por un periodo único y sus dos tercetos, de rimas alternas, se cierran sobre sí mismos (CDC DCD): su tema, empero, es el círculo vicioso y, por tanto, la imposibilidad del yo lírico de salirse de él. La idea del circulus vitiosus se manifiesta aún en otros sonetos: en el número XXVII (CDC DCD), donde la situación del amante se define como «contradicción» insoluble, y también en el número XXXII, (CDE ECD), cuya palabra clave es el «desvarío», o sea, el delirio de la lengua, que, igual que ocurre con el amante, «va a parar donde no querría». Se ve que la construcción sintáctica unitaria, sin punto hasta el final, y los esquemas de rimas que comportan estrofas con rimas cerradas, no constituyen de por sí un significado: todo depende de los elementos semánticos que estas particulares estructuras acogen.

De un examen de los demás géneros líricos se infiere que las estructuras sintácticas continuas son más frecuentes en las canciones que en los sonetos. La canción es más melódica que el soneto: su amplia estructura propende hacia el movimiento ondulante, debido a la alternancia de versos largos y versos breves, de endecasílabos y heptasílabos; pero incluso en este género, la sintaxis cerrada sobre sí se da solamente en ciertas estrofas, y nunca en el conjunto de la composición. De un solo periodo es, sin ir más lejos, la estancia inicial de la Canción primera, que encierra una solemne declaración de fidelidad del amante no correspondido. Garcilaso se inspira aquí en el soneto CXLV de Petrarca, ya imitado por Boscán: «Ponmi ove ,l sole occide i fiori et l'erba», caracterizado por su estructura rigurosamente anafórica (las cuatro estrofas comienzan con la palabra «ponmi») y por su tema de origen horaciano: el «pone me» se repite dos veces también en la Oda I, 22 del poeta venusino, con el sentido "ponme dónde sea, siempre te querré»"s. Si comparamos este soneto con la estrofa inicial de la Canción primera (y no con toda la canción, que ostenta una tonalidad más bien disfórica), podríamos decir, por lo menos a primera vista, que Garcilaso expresa sustancialmente

I3 Sobre la imitación de Boscán, quien reproduce la estrofa anafórica del soneto de Petrarca, véase Prieto (1984: 67-80). 
el mismo pensamiento que Petrarca: la del amante que soportaría cualquier adversidad en cualquier clima del mundo, boreal o meridional, helado o tórrido, si supiese que su dama se encuentra allí. Pero Garcilaso, a diferencia de su predecesor, desarrolla ese concepto en un amplio periodo hipotético, cuya parte ascendente abarca nada menos que once versos, en tanto que la descendente ocupa solo dos; y como el tono no desciende hasta el verso II, se crea con ese crescendo una enorme tensión emocional. La innovación de Garcilaso es, sobre todo, de orden métrico-sintáctico y, por supuesto, rítmico: pero el énfasis, que supone un esfuerzo casi sobrehumano, modifica a su vez el significado de las afirmaciones. Ambos textos tienen una sintaxis circular: en el soneto de Petrarca, la insistencia retórica sugiere la idea de constancia, mejor dicho: de continuidad en el círculo vicioso y, por tanto, la imposibilidad de evitar el sufrimiento (se alude a que el amor no correspondido por Laura existe desde hace quince años ya; el soneto resulta, por tanto, fechable: no es anterior a I342); en la canción del toledano, en cambio, lo que se manifiesta con tanto énfasis es la actitud heroica del caballero, su entrega total a la vivencia amorosa. Los significados, al fin y al cabo, divergen, porque los temperamentos que se expresan en cada uno de estos textos, también discrepan. Una lectura en voz alta hará resaltar aún más esta diferencia:

\section{CXLV}

Ponmi ove ,l sole occide i fiori et l'erba, o dove vince lui il ghiaccio et la neve; ponmi ov'è ,l carro suo temprato et leve et ov'è chi ce ,l rende, o chi ce ,l serba;

ponmi in humil fortuna, od in superba, al dolce aere sereno, al fosco et greve; ponmi a la notte, al dì lungo et al breve, a la matura etate od a l'acerba;

ponmi in cielo, od in terra, od in abisso, in alto poggio, in valle ima et palustre, libero spirto, od a' suoi membri affisso;

ponmi con fama oscura, o con ilustre: sarò qual fui, vivrò com'io son visso, continuando il mio sospir trilustre.

(Petrarca I996: 698)

\section{CANCIÓN I}

Si a la región desierta, inhabitable, por el hervor del sol demasïado y sequedad d'aquella arena ardiente, o a la que por el hielo congelado y rigurosa nieve es intratable, del todo inhabitada de la gente, por algún accidente o caso de fortuna desastrada me fuésedes llevada, y supiese que allá vuestra dureza estaba en su crüeza, allá os iría a buscar como perdido, hasta moriros a los pies tendido.

(De la Vega 20I7: 225)

Pasemos ahora a la Canción tercera, la del destierro, cuya primera estancia puede mostrar cómo Garcilaso es sumamente consciente de la estructura de la estrofa. La estancia de la canción petrarquesca se divide tradicionalmente en fronte (con sus dos pies), eslabón y sirima o coda, y estos términos 
son metáforas del traje femenino: mientras que la fronte es la parte frontal, la sirima o syrma, palabra griega, se corresponde con la cola del vestido. Lo expresado en la fronte, en la primera estancia, sirve de prefiguración: la indicación de lugar «isla en medio del Danubio», esto es, estancia apartada en medio del fluir del tiempo, es metáfora de la condición existencial del yo. El mayor énfasis cae precisamente sobre los dos endecasílabos tres y seis, que describen el hic et nunc de la situación del exiliado: en el verso 3, se nos indica el espacio del aislamiento («cerca el Danubio una isla que pudiera») y, en el verso 6, la condición del sujeto en el tiempo («quien, como estó yo agora, no estuviera»). Las dos expresiones «Danubio una isla», y «estó yo agora», ambas con el acento en la sexta, sirven para construir el centro no solo de estos versos, sino también del poema entero, de cuyo enunciado constituyen, de hecho, una mise en abyme. El movimiento y suave rumor del agua, antes mencionados, son metáforas del paso del tiempo: tienen que ver, asimismo, con el fluir de las estrofas y con el discurso poético actualizado, según queda confirmado en la quinta estancia («Danubio, río divino, / que por fieras naciones / vas con tus claras ondas discurriendo, / pues no hay otro camino / por donde mis razones / vayan fuera d'aquí sino corriendo / por tus aguas [...]»). En la sirima de la estancia primera, finalmente, se evoca el locus amoenus, la naturaleza primaveral, con el canto amoroso del ruiseñor que anticipa la queja a morosa, pero no solo amorosa, del sujeto. En la naturaleza amena reina el tiempo alternado y circular, lo que la distingue del yo lírico, que se encuentra prisionero en medio de un río que desciende hacia el mar: no hay, por tanto, una correspondencia armónica entre ambos. De la naturaleza idílica no se habla más en esta canción: el locus amoenus sirve, sobre todo, de contraste a la disfórica situación del yo; solo el ruiseñor tal vez anticipe el recuerdo amoroso, pues «hace renovar el placer o la tristura». Leamos:

\section{CANCIÓN III}

Con un manso rüido

de agua corriente y clara, cerca el Danubio una isla que pudiera

ser lugar escogido

para que descansara

quien, como estó yo agora, no estuviera;

do siempre primavera

parece en la verdura

sembrada de las flores;

hacen los ruiseñores

renovar el placer o la tristura

con sus blandas querellas,

que nunca, día ni noche, cesan de ellas.

(De la Vega 20I7: 243) 
Concluyamos este panorama con una lectura parcial de la Égloga tercera, cuyo tema principal es el poder transformador de la poesía, capaz de convertir el tiempo de la existencia en tiempo cíclico. El escenario del poema es el valle de Tajo, cerca de Toledo, donde comparecen ante el poeta las cuatro ninfas tejedoras: estamos en una «soledad amena», medio escondida por el espeso follaje, gracias a la incesante labor de la hiedra cuya actividad consiste, a su vez, en tejer. Naturaleza y arte se nos presentan como procesos análogos, aunque de diferente nivel: el agua del río que discurre con lentitud, la tupida vegetación, el «manso viento», las aves, los aromas del «florido suelo» y el sol del mediodía -los cuatro elementos, claro está- son los actores del escenario natural, que recuerda una vez más el clásico locus amoenus, pero, aquí, en evidente función poética: como «soledad sonora», en la que se escucha «un susurro de abejas que sonaba» (las abejas que elaboran la miel significan, aquí, la imitatio, la imitación literaria); y como un lugar especial donde es posible el encuentro de la existencia humana con el mito. Dentro de esta soledad, vemos bordar sus telas a las cuatro ninfas que transforman en tejido artístico los materiales -minerales, vegetales, animales- de la misma naturaleza que las rodea: utilizan el oro del Tajo, el verde de las hojas hiladas y la variedad cromática de las conchas, y los elaboran hasta formar con ellos preciosas obras de arte. Este arte es transformación de vidas, previamente convertidas en narración: transformación de vidas y amores en mitos. Adviértase que las ninfas del Tajo no fabrican sus bordados en el fondo del agua, donde tienen su morada en tanto que criaturas inmortales, sino que los perfeccionan en el espacio de la soledad, accesible tanto a ellas como a los seres humanos. En este lugar intermedio, donde se superponen eternidad y tiempo, las ninfas producen cuatro textos-tejidos dentro del texto-soledad, unos y otro contenidos en el texto-lenguaje que leemos. (La soledad, bien mirada, es arte de primer grado, las telas son arte de segundo grado; y aún se nos da a conocer el contenido del epitafio de Elisa, grabado en la corteza de un álamo y representado en la cuarta tela). Ahora bien: para que se mantenga el carácter intermedio -entre la vida humana y el mito- de esta soledad, es necesario que el sol del mediodía no pueda penetrar en ella y que el río discurra despacio, pues ambos, el sol y el río, son figuras del tiempo que pasa. El opositor principal del sol es la hiedra, en tanto que emblema del estilo bucólico, y lo que desacelera el fluir del agua es la conformación del lugar, la soledad, propicia a la poesía. Escuchemos ahora las primeras octavas de la narración principal, las estrofas 8 y 9, que vienen a continuación del proemio: 
ÉGLOGA III (estrofas VIII-IX)

Cerca del Tajo, en soledad amena, de verdes sauces hay una espesura toda de hiedra revestida y llena, que por el tronco va hasta el altura y así la teje arriba y encadena, que el sol no halla paso a la verdura el agua baña el prado con sonido, alegrando la vista y el oído.

Con tanta mansedumbre el cristalino Tajo en aquella parte caminaba que pudieron los ojos el camino determinar apenas que llevaba. Peinando sus cabellos de oro fino, una ninfa del agua do moraba la cabeza sacó, y el prado ameno vido de flores y de sombras lleno.

(De la Vega 20I7: 243)

El agua del Tajo, en esta «soledad amena», fluye de modo imperceptible. Su movimiento es tan lento que el ojo no adivina bien hacia dónde se dirige la corriente. Se excluyen, aquí, los extremos: el fluir rápido del tiempo destructor y la quietud total, que significaría muerte; se admite, en cambio, una especie de oxymoron entre el tiempo acompasado y la calma casi perfecta. Ahora bien: si deseamos saber cómo el poeta transmite esta delicada sensación, no basta con observar la forma del contenido, sino que conviene echar una mirada también sobre la forma de la expresión. En cuanto a las particularidades métricas, percibimos primero un procedimiento yámbico puro, típico de quien «camina» («con tanta mansedumbre el cristalino / Tajo»: 2, 4, 6, 8 Io), pero en el verso siguiente se nos aparece, de repente, una sucesión de sílabas leves que casi no llevan acento, y esta irregularidad rítmica, esta cadencia dactílica, acelera el movimiento del verso: «Tajo en aquella parte caminaba / que pudieron los ojos el camino / determinar apenas que llevaba», (yo leo: I, 4, 6, 8, Io / 3, 6, Io / I, 4, 6, I0). «Tajo en aquella», «pudieron los ojos», «determinar» son cadencias dactílicas, que se alternan con las yámbicas. Un efecto bien llamativo de aceleramiento lo producen asimismo los dos enjambements («el cristalino / Tajo» y «el camino / determinar»). Llama la atención, además, el orden de las palabras, sobre todo la disyunción sintáctica entre el sustantivo «el camino» y la relativa «que llevaba», de él dependiente. Tampoco quiero olvidarme del hipérbaton («de verdes sauces una espesura»), ya señalado debidamente por Dámaso Alonso en su célebre lectura estilística de esta égloga, sobre la que nosotros, cuando estudiantes, 
nos hemos formado (Alonso I95I: 47-I08). El poeta no solo sugiere la idea de un movimiento casi imperceptible, sino que nos hace partícipes, emotivamente, de esta sensación.

Huelga recordar que, de las cuatro telas bordadas por las ninfas, tres tratan sobre mitos antiguos (Orfeo y Eurídice, Dafne y Apolo, Venus y Adonis) y, la última, sobre una historia moderna, que va convirtiéndose, a su vez, en mito: los amores de Nemoroso y Elisa, que es Isabel Freyre, una dama portuguesa, la amada toledana del poeta, muerta en I533 o I534. No quiero detenerme a analizar el sentido meta-poético de los mitos clásicos, porque lo han hecho ya varios críticos, ante todo Elías L. Rivers y Anne J. Cruz. Me detendré a examinar, en cambio, lo que ocurre en el centro del poema que, considerado en su totalidad, comprende 47 octavas, de las que siete forman el proemio (la secuencia A) y cuarenta el relato propiamente dicho (la secuencia B $)^{14}$. Si partimos de la idea de que la narración abarca cuarenta octavas, se nos revela con claridad meridiana la posición central del mito de Nemoroso y Elisa, descrito entre las estrofas XXV y XXXIII, que ocuparían las posiciones I8 hasta 26 dentro de la secuencia B. Debo precisar que en el mito moderno se evocan, por un lado, los trágicos amores de Elisa y Nemoroso y, por otro, la ciudad de Toledo, escenario privilegiado de estos sucesos. La descripción de la ciudad imperial se sitúa, a su vez, en el momento central de la narración; e inmediatamente después, se nos describe el entierro de Elisa, representado en la tela tejida por «la blanca Nise».

Veamos, ahora, esta descripción de Toledo cuyo protagonista es de nuevo el río Tajo, ya no visto desde el escenario bucólico de la vega toledana, sino como un río impetuoso, que baña el monte sobre el que se erige la venerable ciudad y que, aparentemente, desea contenerla por completo en un círculo perfecto, pero que se ve obligado a abandonar ese propósito y a «seguir su jornada» hacia el Oeste. Puede hablarse, aquí, de una mise en abyme, ya que el río Tajo es actor no solo del primer nivel de ficción, sino también de esta representación artística, de esta tela, que a mi modo de ver encierra el significado central del poema. Pero leamos primero las tres octavas:

ÉGLOGA III (estrofas XXV-XXVII)
La blanca Nise no tomó a destajo de los pasados casos la memoria, y en la labor de su sotil trabajo no quiso entretejer antigua historia; antes, mostrando de su claro Tajo en su labor la celebrada gloria, la figuró en la parte donde él baña

I4 Sobre los problemas de segmentación de este texto, véase Güntert (20I2: 43-52). 
la más felice tierra de la España.

Pintado el caudaloso río se vía, que, en áspera estrecheza reducido, un monte casi alrededor ceñía, con impetu corriendo y con rüido; querer cercarlo todo parecía en su volver, mas era afán perdido; dejábase correr en fin derecho, contento de lo mucho que había hecho.

Estaba puesta en la sublime cumbre del monte, y desde allí por él sembrada, aquella ilustre y clara pesadumbre de antiguos edificio adornada. De allí con agradable mansedumbre el Tajo va siguiendo su jornada y regando los campos y arboledas con artificio de las altas ruedas.

(De la Vega 20I7: 459)

El río Tajo, que en la soledad simbolizaba el tiempo acompasado, aquí se convierte en figura del deseo impetuoso, que por un lado intenta cercar la ciudad y que, por otro, en tanto que metáfora de la voluntad del poeta, anhela eternizar la vida. Ambos, el río impetuoso y el poeta, quieren alcanzar la perfección y casi lo consiguen: el círculo, esta vez, es efectivamente una imagen de la eternidad y del mito. Pero del mismo modo que el Tajo casi logra realizar lo absoluto, aunque no del todo, por lo que a la postre tiene que abandonar su empresa y seguir su camino hacia el mar, que es su muerte, así la poesía de Garcilaso, deseosa de superar el tiempo, debe aceptar su condición temporal dentro del orden general de las cosas, que ve surgir y declinar épocas y culturas. La alusión a las nuevas máquinas de los ingenieros toledanos debe interpretarse, a su vez, como un claro indicio de modernidad: las «altas ruedas» no son solo las de las azudes o presas, empleadas para extraer agua del río; Garcilaso debió de tener en cuenta también las que construyera el arquitecto Juanelo Turriano, Gianello Torriano originario de Cremona y contratado por Carlos $\mathrm{V}$ para asegurar el abastecimiento de agua en Toledo (= el artificio de Juanelo).

La mise en abyme de las estrofas XXVI y XXVII expresa, así, tanto el deseo de perfección, propio de este poema, como la conciencia de la necesidad de volver a la historia y de abrirse a sus contingencias. Sabido es que la Égloga tercera no termina con la descripción de las cuatro telas y que su tema no es la sublimación de la vida en arte: Garcilaso, aquí, contrariamente a lo que ha sostenido Rafael Lapesa, no se refugia en el esteticismo (Lapesa I968 $2^{\text {a }}$ 
ed.: I66). Es cierto que el ciclo de las transformaciones llega a su cumbre con la evocación de la muerte de Elisa. Pero el discurso del poeta no acaba con ese episodio: no solo contemplamos los magníficos resultados del proceso transformador que convierte, en las telas, la vida en arte; sino que se nos muestra también el retorno a una forma de arte más elemental. Las cuatro ninfas, después de haber bordado toda la tarde, se convierten, a partir de la octava XXXVI, en oyentes pacíficas del canto amebeo de dos jóvenes pastores, cuyo canto brota de la pasión recién nacida y representa una expresión artística primigenia, juvenil y a la vez contemporánea, a través de la cual se nos hace volver a los comienzos del ciclo transformador: de ese ciclo que parte de la vida de las pasiones y se perfecciona a través de los siglos, alcanzando algunas veces momentos verdaderamente culminantes, como ocurrió en la obra de nuestro poeta.

\section{Bibliografía}

Alighieri, Dante (1957³), De vulgari eloquentia, ed. de Aristide Marigo, Firenze, Le Monnier.

Alonso, Dámaso (I95I), «Garcilaso y los límites de la estilística», Poesía española, Madrid, Gredos, pp. 47-Io8.

Beltrami, Pietro G. (20I5), «Endecasillabo, décasyllabe e altro», en L'esperienza del verso. Scritti di metrica italiana, Bologna, Il Mulino, pp. I89-24I.

Bembo, Pietro (1967), Prose della volgar lingua, ed. de Mario Marti, Padova, Liviana.

Blecua, José Manuel (I982), «Introducción», Poesía de la Edad de Oro, vol. I, Renacimiento, Madrid, Castalia, pp. 7-I7.

Boscán, Juan (1999), Obra completa, ed. de Carlos Clavería, Madrid, Cátedra.

-. (I999), Poesía, ed. de Pedro Ruiz Pérez, Madrid, Akal.

Cueva, Juan de la (1965), El infamador, Los siete infantes de Lara y el Ejemplar poético, Madrid, Espasa-Calpe.

De la Vega, Garcilaso (1574), Obras del Excelente Poeta Garcilaso de la Vega, con Anotaciones y Enmiendas del Licenciado Francisco Sánchez, Salamanca, Pedro Lasso.

-. (I98I), Obras completas, ed. Elias L. Rivers, Madrid, Castalia.

-. (20I7), Poesía castellana, ed. de Julián Jiménez Heffernan e Ignacio García Aguilar, Madrid, Akal.

Denores, Giason (I973), «Discorso», en: Weinberg, Bernard, Trattati di poetica e retorica del '500, 4 vols., Bari, Laterza, III, pp. 409-4IO.

Dionisotti, Carlo (I960), «Introduzione», en Pietro Bembo, Prose della volgar lingua. Prose e rime, Torino, UTET, pp. 9-70. 
Güntert, Georges (20I2), De Garcilaso a Gracián. Treinta estudios sobre la literatura del Siglo de Oro, ed. de Itzíar López Guil et al., Vigo, Academia del Hispanismo.

Herrera, Fernando de (200I), Anotaciones a la poesía de Garcilaso, ed. de Inoria Pepe y José María Reyes, Madrid, Cátedra.

Lapesa, Rafael (1968²), La trayectoria poética de Garcilaso, Madrid, Revista de Occidente.

Márquez, Miguel Ángel (2009), «Ritmo y tipología del endecasílabo garcilasiano», Revista de Literatura, LXXI, I4I, pp. II-38.

Minturno, Antonio Sebastiano (2009), Arte poética, ed. y traducción de $\mathrm{M}^{\mathrm{a}}$ del Carmen Bobes Naves, Madrid, Arco Libros.

Navarro Tomás, Tomás (I973), «Correspondencia prosódica-rítmica del endecasílabo", Los poetas en sus versos: desde Jorge Manrique a García Lorca, Barcelona, Ariel, pp. 89-II5.

-. (1986), Métrica española, Barcelona, Labor.

Porqueras de Mayo, Alberto (I986), La teoría poética en el Renacimiento y Manierismo españoles, Barcelona, Puvill.

Petrarca, Francesco (1996), Canzoniere, ed. commentata da Marco Santagata, Milano, Mondadori.

Prieto, Antonio (I984), La poesía española del siglo XVI, 2 vols., Madrid, Cátedra.

Tasso, Bernardo (1972), «Ragionamento della poesia», en Weinberg, Bernard, Trattati di poetica e retorica del '50o, II, pp. 569-584.

-. (I97I), Gerusalemme Liberata, prefazioe e note di Lanfranco Caretti, Torino, Einaudi.

Weinberg, Bernard (I970-I974), Trattati di poetica e retorica del '50o, Bari, Laterza. 